International Journal of Engineering \& Technology, $7(2.8)(2018) 298-302$
SPC
International Journal of Engineering \& Technology
Website: www.sciencepubco.com/index.php/IJET
Research Paper

\title{
Explicit analysis of heavy vehicle chassis structure for the effect of frequency response
}

\author{
Ramesh kumar.S ${ }^{1}$ Raja sankar.M ${ }^{2}$, Harish.V ${ }^{3}$, Arun kumar.K ${ }^{4}$, Gokulakrishnan.T ${ }^{5}$, Madan.M ${ }^{6}$ \\ ${ }^{1}$ Assistant Professor, ${ }^{2}$ Associate Professor, Department of Mechanical Engineering, \\ Karpagam College of Engineering, Coimbatore, Tamilnadu, India. \\ ${ }_{3,4,5,6} U G$ students, Department of Mechanical Engineering \\ Karpagam College of engineering, Coimbatore, Tamilnadu, India. \\ *Corresponding author E-mail: ${ }^{1}$ srkkce@gmail.com
}

\begin{abstract}
The current circumstance in industry is an entire looked for after of trucks on the cost and weight points and in addition too on upgraded total vehicle features and general work execution. The case accept a key part in the layout of any truck. Truck suspension outlines the helper spine of a business vehicle. The essential limit of the truck case is to enable the parts and payload to set upon it. Exactly when the truck comes the road, the body is subjected to vibration prompted by road offensiveness and excitation by vibrating parts mounted on it. The responses of the truck body which fuse the weight allocation and movement under various stacking condition are furthermore viewed. The mode shape occurs choose the sensible mounting zones of portions like engine and suspension system. A couple of changes are moreover proposed to decrease the vibration and to upgrade the nature of the truck frame. The skeleton design when all is said in done is a baffling methodology and to reach at an answer which yields a good execution is a horrid endeavor. Since the suspension has an unusual geometry and stacking outlines, there is no inside and out portrayed investigative technique to separate the case. So the numerical course of examination is grasped, in which Finite Element Technique is most by and large used course.
\end{abstract}

Keywords: Chassis, Finite Element Technique, ANSYS Work Bench 15.0, geometry, scientific, mode shape.

\section{Introduction}

There are various mechanical zones using this vehicle for their transportations, for instance, the coordination, agribusinesses, creation lines and diverse endeavors. If any of the excitation frequencies agrees with the trademark frequencies of the vehicle undercarriage, by then resonation ponder happens. The body will encounter hazardously broad movements, which may provoke over the best evasion and disappointment. The vibration of the casing will in like manner cause high weight centers at particular territories, exhaustion of the structure, loosening of mechanical joints, development of clatter and vehicle bother. To handle these issues, mull over on the vehicle body for dynamic properties is exceptionally essential. The torsion strength and measured parameters were settled probably and a while later used to favor the constrained part demonstrate finally the case was moved up to manufacture the essential solidness. It was seen that the torsion mode overpowered the typical repeat. A skeleton includes an internal structure that support a man-made dissent in its improvement and use.

It is similar to an animal's skeleton. An instance of an undercarriage is the under piece of a motor vehicle, containing the edge (on which the body is mounted). In case the running contraption, for instance, deals, and on occasion even the driver's seat, are consolidated then the social gathering is depicted as a moving undercarriage.

The body is the framework that is everything joined to it in a vehicle undercarriage of hub of venturing stool plot make which has two side people and five transverse people called cross people from box cross portion. The edge has been shown in catia programming using certifiable estimations. FEA examination was done using ANSYS Software compelling and strong transports require a capable and reliable body. Like in the new Quoin. With first class fragments and verifiable versatility for straightforward adaption to your business. In addition, since we know every kilo counts, we have streamlined every single bit of the skeleton to diminish the general weight. The result upgraded payload for improved gainfulness and fuel-capability.

\section{Literature Review}

The writing survey of the truck body was completed to get the essential comprehension of the undertaking. Data like run of the mill regular recurrence estimations of truck body, excitation sources and mode state of truck case were sought and inspected. At that point the measurement of a current truck frame was estimated. The kind of suspension was known as parallel stepping stool compose outline with box segment. The ensuing stage was the undercarriage helper course of action and set up for estimation purposes. The estimation of Frequency Response Function(FRF) data was performed and there were 22 estimation raises out the undercarriage structure. The FRF data were then changed into ME's Scope programming for advance examination on Modal Analysis.

\section{Solution Methodology}

The response for the issue is performed in three stages Theoretical Analysis, Creating a Solid Model, Finite Element Analysis. 


\subsection{Theoretical Analysis}

Hypothetical Analysis is performed by using the major thoughts of Strength of Materials. The Chassis Ladder of this issue is considered as an overhanging column with roller supports identifying with front and back wheels. Signify stack following up on the Chassis is taken as a sum of breaking point of the casing and weight of the body and engine. This total load is considered as reliably circled stack acting all through the navigate of the bar Reaction powers, Shear powers and Bending minute are figured in light of the total load.

\subsection{Creating a Solid Model}

A 3D in model of traditional Ladder outline suspension framework is drawn on the modernized using SOLIDWORKS. This 3D Model is bring into Ansys15.0 for Finite Element Analysis.
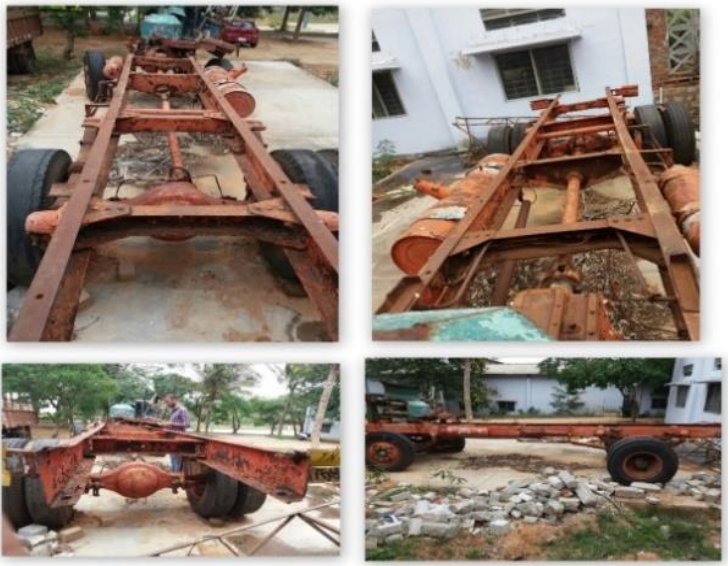

Fig. 3.2: Photography

\section{Modelling Software}

SolidWorks is a natural Computer-Aided Design and Computer Aided Manufacturing structure. The CAD limits robotize the run of the mill building, layout and drafting capacities found in the present amassing associations. The CAM limits give NC programming to show day machine instruments using the SolidWorks design model to depict the finished part. Solidworks is totally three dimensional, the twofold precision structure that licenses to exactly depicting any geometric shape. By solidifying these shapes, one can design, inspect, and make delineations of things.

\subsection{FEM Modelling}

This part contains showing of the casing and applying stacking conditions and after that dealing with the issue with the help of ANSYS programming.

ANSYS is a run of the mill arrange for dealing with planning issues. Customary endeavors you can perform in Workbench are:

- Importing models from a grouping of CAD structures.

- Conditioning models for layout propagations using the Design Modeler.

- Performing FEA reenactments using Simulation

- Optimizing traces using Design Explorer or Design Explorer VT. The underlined words above are the names of different processors inside ANSYS Workbench . Basically, you will use the Design Modeler to make the geometry and the Simulation to set up the materials, FE-work, weights and breaking point conditions, deal with the issue and analyze the results. The standard interface ANSYS Classic (used as a piece of the primary PC workshop) is up 'til now the focal point of ANSYS. ANSYS Workbench is another bleeding edge interface with extra cutting edge limits, for example, the blend of CAD geometries.

\subsection{DESIGN MODELLER}

Plan Modeler is expected to be used as a geometry administrator of existing CAD models. Framework Modeler is a parametric part based solid modeler arranged with the objective that you can normally and quickly begin drawing 2D depicts, exhibiting 3D segments, or exchanging 3D CAD models for building examination pre-handling.



Fig. 4.2 a: Truck chassis

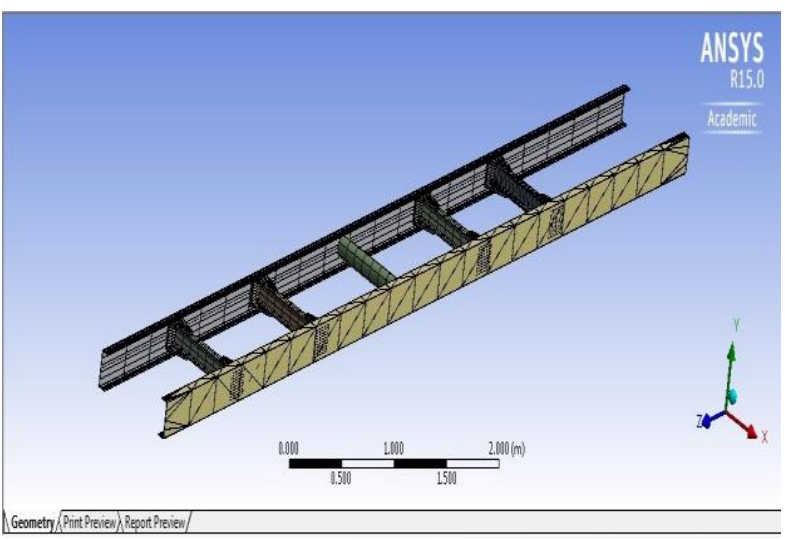

Fig. 4.2 b: Meshing

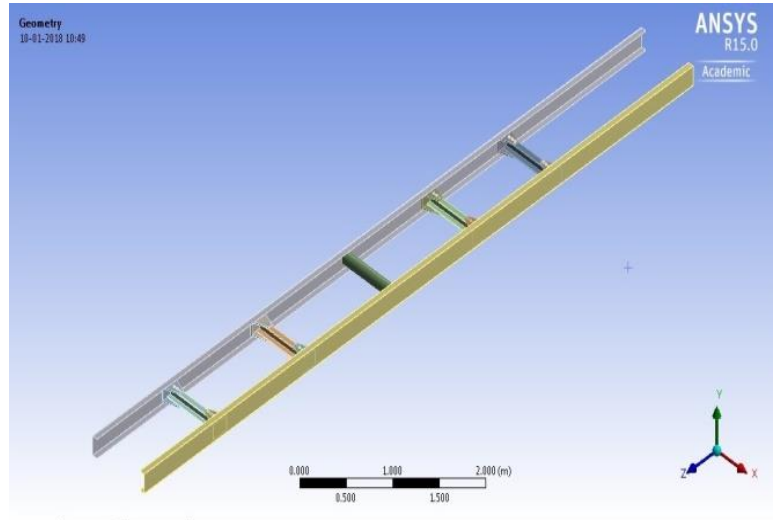

Fig. 4.2 c: Geomentry

\subsection{Finite Element Model}

The truck body was exhibited by using 10noded tetrahedral (Tet10) in number parts. Trial and numerical examinations on an essential discharge rectangular straight column prescribed that Tet10 segment can work the truck suspension geometry as showed up in and give exact outcomes of the typical frequencies and the 
mode shapes. There are two sorts of examination finished; standard mode examination to choose the trademark frequencies and the mode shapes, and the straight static weight examination to research the weight apportionment and contortion case of the case under static load.

\section{Modal Analysis Results}

Modular examination is a kind of straight examination advancement, used to choose the structure of the standard repeat and vibration mode. In run of the mill mode examination, the typical frequencies got are used to relate to the working conditions of the truck while the mode shapes are used to choose if the mounting territories of parts on the truck body are fitting. A preliminary report was finished in choosing as far as possible conditions for the undercarriage. A without free breaking point condition was picked as it is generously more direct to test probably in this condition if required. Therefore, two sorts of sans free utmost conditions were attempted. The important make is with no goal and the other kind is applying spring limit condition to the truck undercarriage. It was shown that both point of confinement conditions gave undefined estimations of the standard repeat.

\subsection{Mode Shapes of Structural}

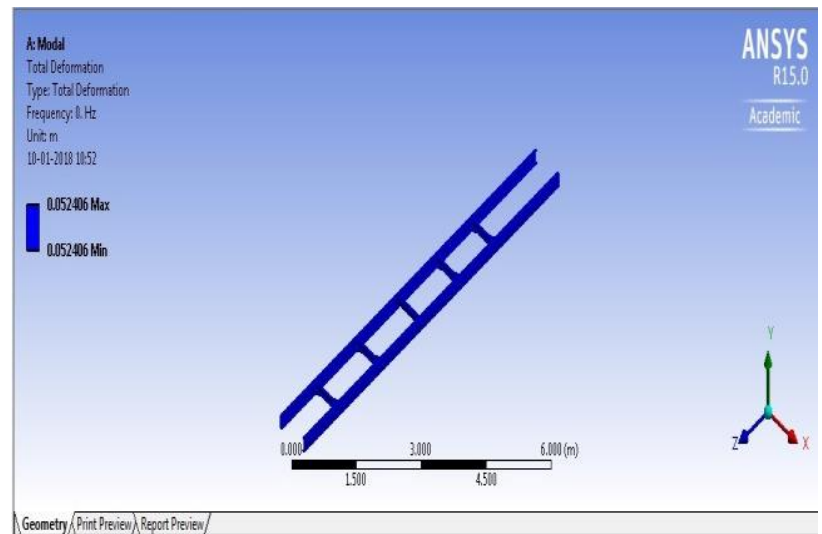

Fig. 5.1 a: Mode 1



Fig. 5.2 b: Mode 2

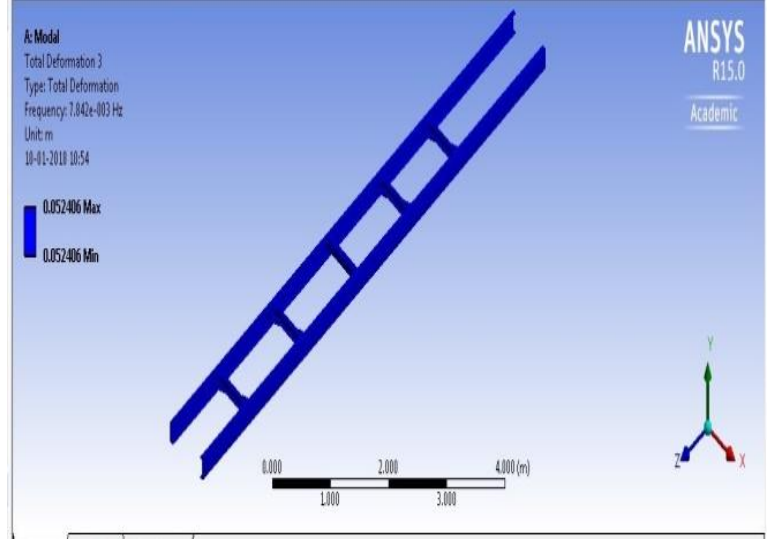

Fig. 5.3 c: Mode 3

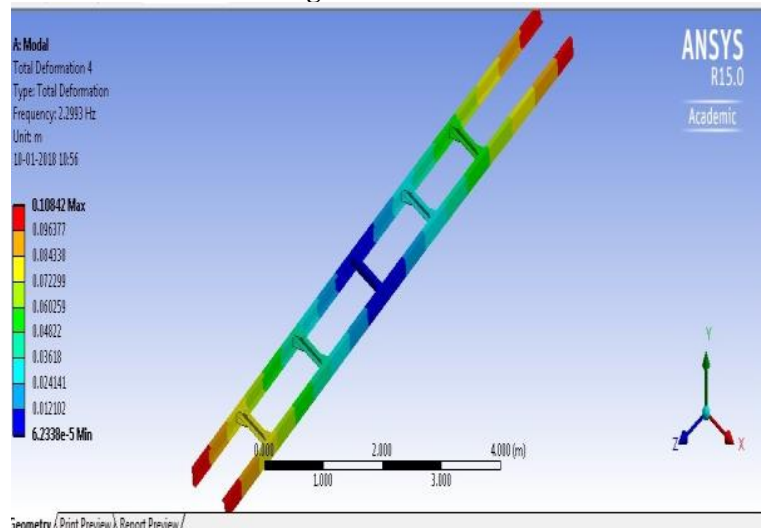

Fig. 5.4 d: Mode 4

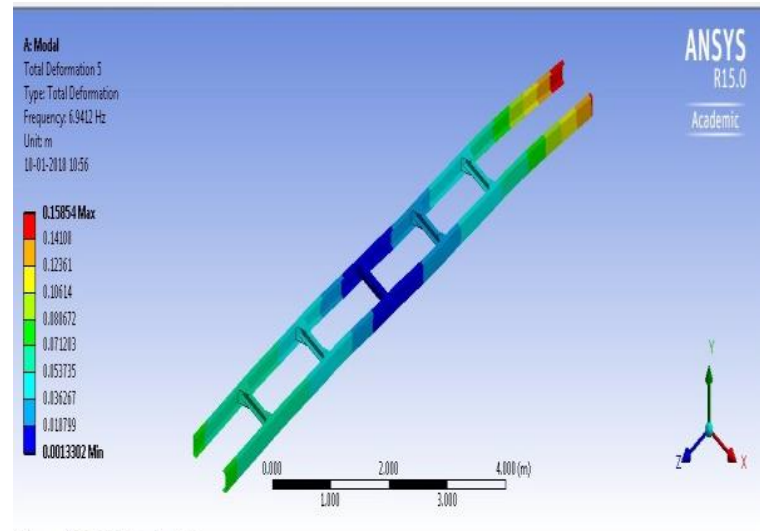

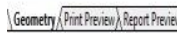

Fig. 5.5 e: Mode 5

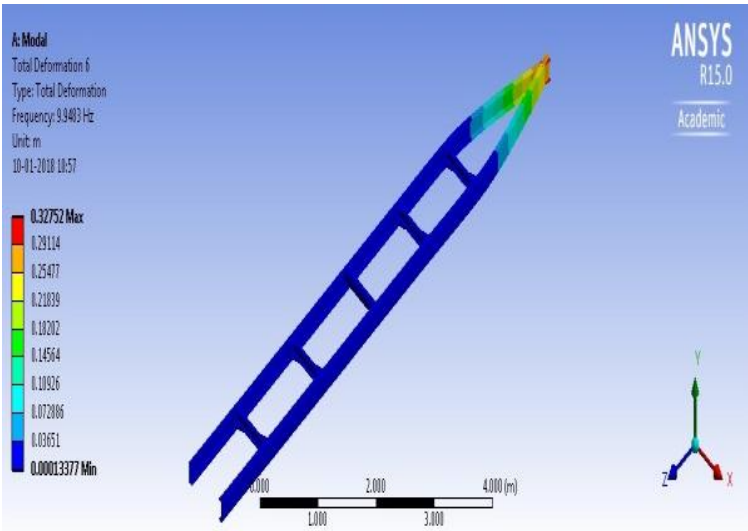

Fig. 5.6 f: Mode 6 


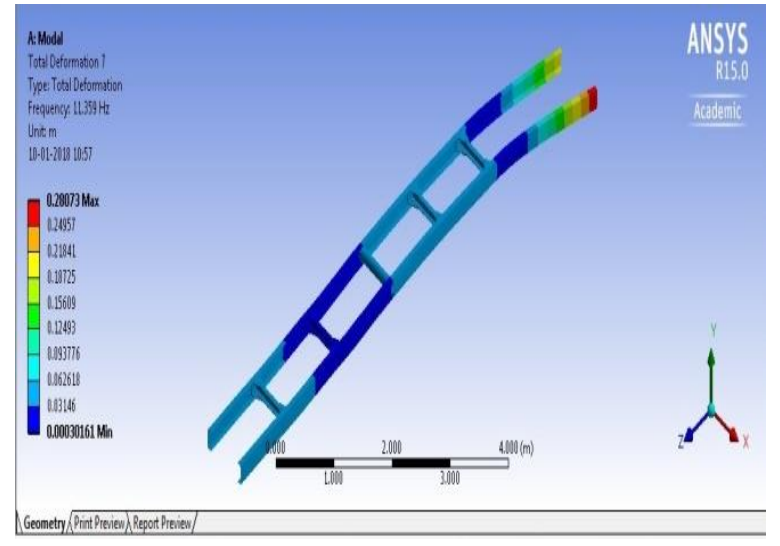

Fig. 5.7 g: Mode 7

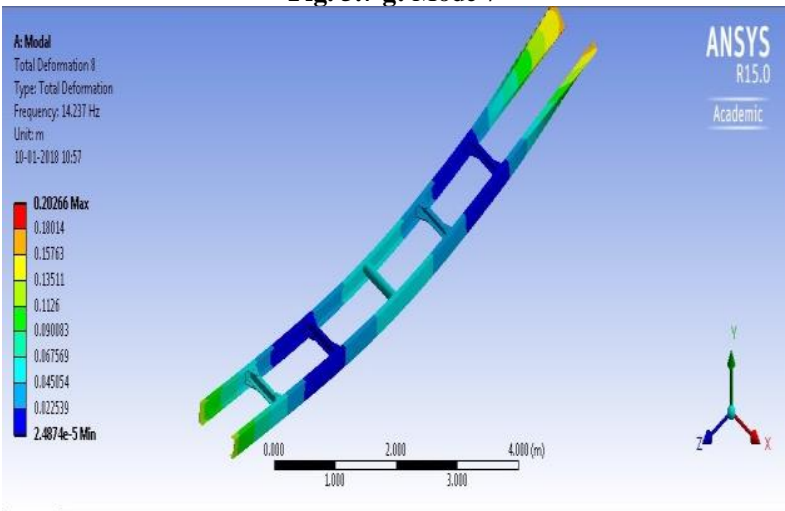

Geometry/Print Prenien, Report Preview

Fig. 5.8 h: Mode 8

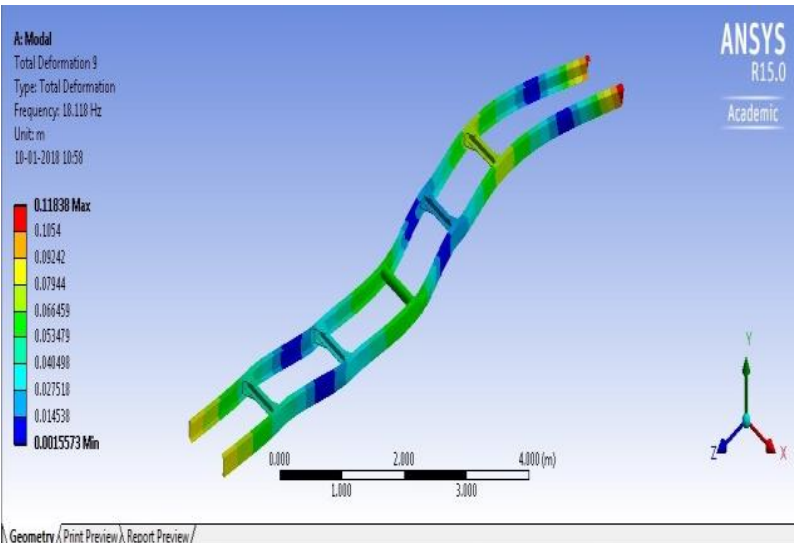

Fig. 5.9 i: Mode 9

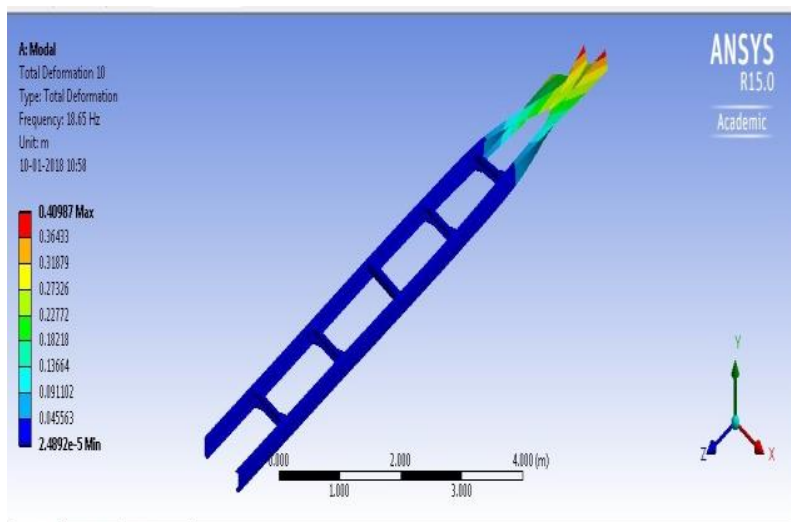

Fig. $\mathbf{5 . 1 0}$ j: Mode 10

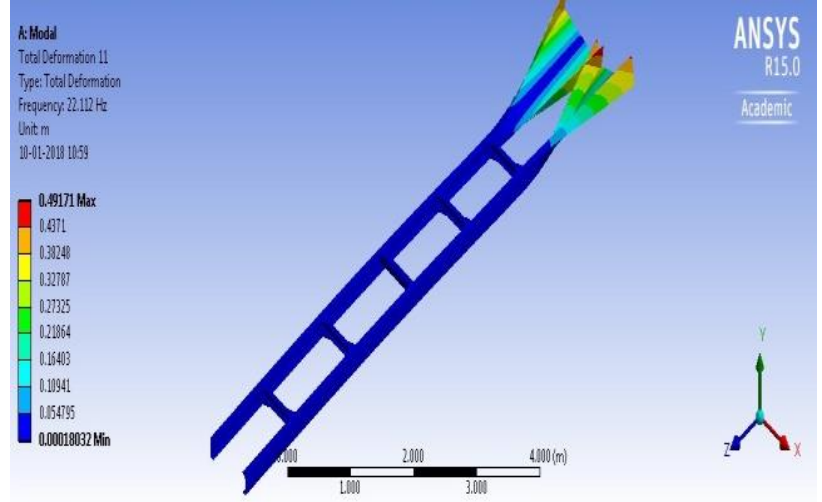

Geometrys Print Previauh Repoot Preieier

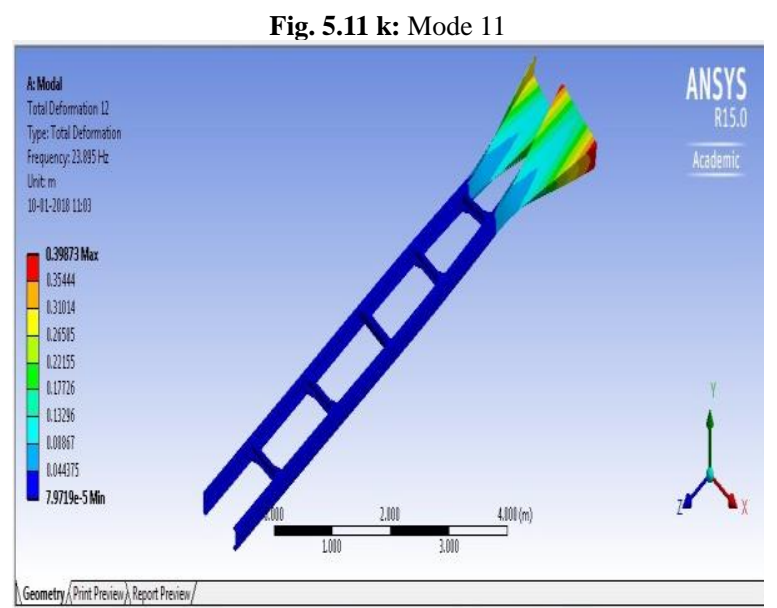

Fig. 5.12 L: Mode 12

\section{Conclusions}

Secluded examination is a sort of straight examination headway, used to pick the structure of the standard rehash and vibration mode. In ordinary mode examination, the run of the mill frequencies got are utilized to identify with the working states of the truck while the mode shapes are utilized to pick if the mounting regions of parts on the truck body are fitting. A preparatory report was done in picking beyond what many would consider possible conditions for the undercarriage. A without free limit condition was picked as it is liberally more straightforward to test likely in this condition if required. Along these lines, two sorts of sans free most extreme conditions were endeavored. The essential make is with no objective and the other kind is applying spring limit condition to the truck undercarriage. It was demonstrated that both purpose of control conditions gave vague estimations of the standard rehash.

\section{References}

[1] Dave Anderson and Grey Scheme, " Development of a MultiBody Dynamic Model of a Tractor - Semi trailer for Ride Quality Prediction", International Truck and Engine Corp. 2001.

[2] I.M. Ibrahim, D.A.Crolla, and D.C. Barton, "Effect Of Frame Flexibility On The Ride Vibration Of Trucks", Department of Mechanical Engineering, University of Leeds LS2 9JT, U.K. August 1994.

[3] Pomulo Rossi Pinto Filho, "Automotive Frame Optimization", Universidade Federal de Uberlandia. November 2003.

[4]Zaman @ Bujang, Izzudin and Abd. Rahman, Roslan (2006), "Application Of Dynamic Correlation Technique And Model Updating on Truck Chassis", 1 st Regional Conference on Vehicle Engineering \& Technology, July 2006.

[5] Lonny L. Thomson, Jon K. Lampert, and E. Harry Law, "Design of a Twist Fixture to measure the Torsional Stiffness of a Winston 
Cup Chassis", Department of Mechanical Engineering, Clemson Univ.1998.

[6] Murali M.R. Krishna, "Chassis Cross-Member Design Using Shape Optimization", Internasional Congress and Exposition Detroit, Michigan. February 2326,1998.

[7] Wesley Linton, "Analysis of Torsional Stiffness and Design Improvement Study of a Kit Car Prototype", Cranfield University, September 2002.

[8] Marco Antonio AlvesJr, Helio Kitagawa and CelsoNogueira, “ Avoiding Structural Failure Via Fault Tolerant Control - An Apllication on a Truck Frame", Detroit, Michigen November 18$20,2002$.

[9] 9.http://www5.jeep/vensuite/vehiclecompare.jsp

[10] JeroenDeweer and Tom Van Langenhove, " Identification of the Best Modal Parameters and Strategies for FE Model Updating", Society of Automotive Engineers, 2001.

[11] Wesley Linton, "Analysis of Torsion Stiffness and Design Improvement Study of A Kit Car Chassis Prototype", Cranfield University 2001-2.

[12] Lonny L. Thomson, Pipasu H. Soni, SrikanthRaju, E. Harry Law, " The Effects of Chassis Flexibility on Roll Stiffness of a Winston Cup Race car", Departmental of Mechanical Engineering, Clemson University, 1998.

[13] "ME'sope VES: Demo Guide", Vibrant Technology Inc., Central of America, 2003

[14] N. Moller, S.Gade, "Application of Operational Modal Analysis on Cars", SAE Paper 2003-01-1599, Noise \& Vibration Conference and Exhibition Traverse City, Michigan, 2003.

[15] C.Cosme, A.Ghasemi, J.Gandevia, "Application of Computer Aided Engineering in the Design of HeavyDuty Truck Frames", SAE Paper 1999-01-3760, International Truck \& Bus Meeting \& Exposition, Detroit, Michigan, 1999.

[16] "FEMtools Theoretical Manual", Dynamic Design Solution NV, Leuven, Belgium, 2002.

[17] D.J.Ewins, "Modal Testing: Theory and Practice". Research Studies Press Ltd., Hertfordshire, England, 1984.

[18] MohdJailaniMohdNor, Shahrum Abdullah, Nordin Jamaluddin, Rozmi Ismail, Sallehuddin Mohamed Haris and AzliArifin, "The regional conference on advances in noise, vibration and comfort", Faculty of engineering, UKM, 2007.

[19] Kenneth H.Huebner, Earl A.Thorton, Ted G.Byrom, "The Finite Element Method For Engineers", Third Edition.

[20] J.William Fitch, "Motor Truck Engineering Handbook Fourth Edition”, SAE Inc., Warrendale, U.S.A, 1993. 